\title{
Urban Land Use Early Warning System for Shenzheng City
}

\author{
JIANG Renrong ${ }^{1}$, WANG Hao ${ }^{1}$, LI Hongga ${ }^{1 *}$, Liu Lin $^{2}$, HUANG Xiaoxia ${ }^{1}$ \\ 1. Institute of Remote Sensing Applications Chinese Academy of Sciences Beijing, China \\ 2. Wuhan Research Institute of Surveying and Mapping Wuhan, China
}

\begin{abstract}
Land is a sustainable renewable resource important for its huge influence on environment, society and economy. In this paper, a new framework was put forward to building urban land use spatial early warning system. In the proposed approach, system dynamic model (SD), cellular automata model (CA), temporal remote sensing data and geographical spatial analysis were integrated for Shenzhen land use spatial prediction and warning. SD model was applied for linking the socio-economic index, policies factors and land use area into a loop network at regional levels. Meanwhile, CA model was used to compute transitional probabilities of each cell in order to simulate land use changes. Based on land use control indices, spatial distribution of land use alert status was obtained. The results showed that the system had the ability to reflect the complex behavior of land use system, and met the needs of land use early warning systems and annual planning of land supplies of Shenzhen municipality.
\end{abstract}

Index Terms - urban land use, early warning system, system dynamic model, cellular automata model.

\section{INTRODUCTION}

Land resource, non-renewable resources important to the whole world and influence to environment, society and economy, has been paid increasing attention to. Urban land use system presents more complex dynamics resulting in environmental, economic, social problems different from rural land. In China urban land use lacks rational utilization and planning and it seems to be required extremely urgent to prevent problems caused by high speed of city growing. Land shortage and space limitation of Shenzhen actually becomes the main contradiction for land management and planning in the past decades, for sake of rapid spreading of the city. Consequently, assessing land use system scientifically, reflecting land use problems objectively and building land use warning index system are extremely important ${ }^{[1][2]}$. The proposed urban land use prediction and warning system is aimed to enhance the ability of land use prediction and warning and improve its credibility and accuracy. The key simulation and prediction model is based on the integration of SD model and CA model. And several land use control indices were brought in for obtaining spatial distribution of land use alert
In the second section, background of land use warning system is introduced. Data preparation especially temporal remote sensing data preparation was depicted in the third section. SD and CA models as key land use scenario models is depicted in the fourth section. The fifth section is the structure of the urban land use early warning system and several functions of its subsystems. After that, system warning results and analysis will be showed and conclusion that the system meets the needs of land use early warning systems and annual planning of land supplies of Shenzhen municipality will be drawn at last.

\section{BACKGROUND}

Warning system is aim to give early warning of disasters or something bad before happening by series of simulation and prediction with prepared historical data and experiences so that prevention and measures can be taken in advance to relive damage and loss. For the last decades, land use warning research has been gaining tremendous attention, most of which separately focus on land use changes models and warning indexes. Stephenne ${ }^{[3]}$ proposed a dynamic simulation model for land use changes in Sudano-sahalian countries of Africa. Verburg $^{[4]}$ built CLUE-S model a land use change model at the regional scale. Overmars ${ }^{[5]}$ studied spatial autocorrelation in multi scale land use models. $\operatorname{Tan}^{[6]}$ and $\mathrm{Qia}^{[7]}$ discussed on early warning indicator system for sustainable, intensive use of urban land, respectively. In this paper, we concentrated on land use prediction model of urban land use and proposed our own warning indexes in the warning system.

Advanced technology such as RS, GIS and others also become important platform for study of land use warning, which can help make land use research more visualized, dynamic, profound and detailed. Our urban land use early warning system was a research for Shenzhen land use which used a dynamic land use model integrated by SD and CA models, historical remote sensing data as an important data source, and GIS technology to build a platform for management and visualization. Especially, it focused on urban land use and emphasized on land use prediction, simulation and optimization.

\footnotetext{
*Author to whom correspondence should be addressed.

E-mail: lihongga@irsa.ac.cn; Tel: 86-10-64850282.
} 


\section{DATA PREPARATION}

Historical remote sensing images were collect and classify in order to prepare time series land use maps. All data used in this method are listed as follows: (1) historical Remote Sensing (RS) images from Multispectral Scanner (MSS), Thematic Mapper (TM), and Enhanced Thematic Mapper (ETM) of Landsat from years 1986 to 2000, and auxiliary RS data from China Brail Earth Resource Satellite (CBERS) from years 2000 to 2010; (2) statistic data from real estate research center (RERC) including the land utilization alteration data from 1996 to 2010 and detailed investment data of second category land.

Series land use maps from 1990 to 2008 were prepared by date processing of used data and used for land use simulation. Meanwhile, independent variables were extracted by geographical information system, which were used to measure the physical suitability, accessibility to infrastructure and facilities, market factors and others for every land use cell.

\section{KEY MODELS}

SD model ${ }^{[8]}$ and CA model ${ }^{[9]}$ were two main land use scenario models we chose in simulating land use conditions. We applied an improved urban land use scenario model by the integration of $\mathrm{CA}$ and $\mathrm{SD}$ models ${ }^{[10]}$ in this paper to provide GIS analysis for the scenarios simulation system in order to obtain more accuracy of the predictions by considering their advantages and weakness.

\section{SD model}

In land use system, connections among socio-economic index, policies factors and regional land use conditions were extremely complicated. SD model is one model specialized in depicting such connections. It made positive and negative feedbacks of mutual influence especially on industrial and residential land use in the early system to make prediction of changing amount of each land.

According to statistical year book of Shenzhen and house estate investigation data from 1990 to 2008, variables for policies factors and socio-economic index, such as business climate index, fixed assess investment, entrepreneur confidence index, industrial climate index, GDP, technical innovation, population, population increase ratio, industrial land price, supply of fresh water, per capita income, house price, real estate index, demolition, export, purchase power index, per capita residential demand land and so on. Figure 1 showed two detailed SD models for Shenzhen industrial and residential land.

\section{GeoFeature-CA model}

GeoFeature-CA model was used to spatialize the land use predictions and controlling areas in order to model the land use patterns of the different land use scenarios demands. Seven independent variable layers including the population density, slope, the distance to major roads, the distance to railways, the distance to central business districts, the distance to industry districts and the distance to education centers were selected to compute the suitability of each cell in the CA model.

Fig 1. SD models for Shenzhen industrial and residential land

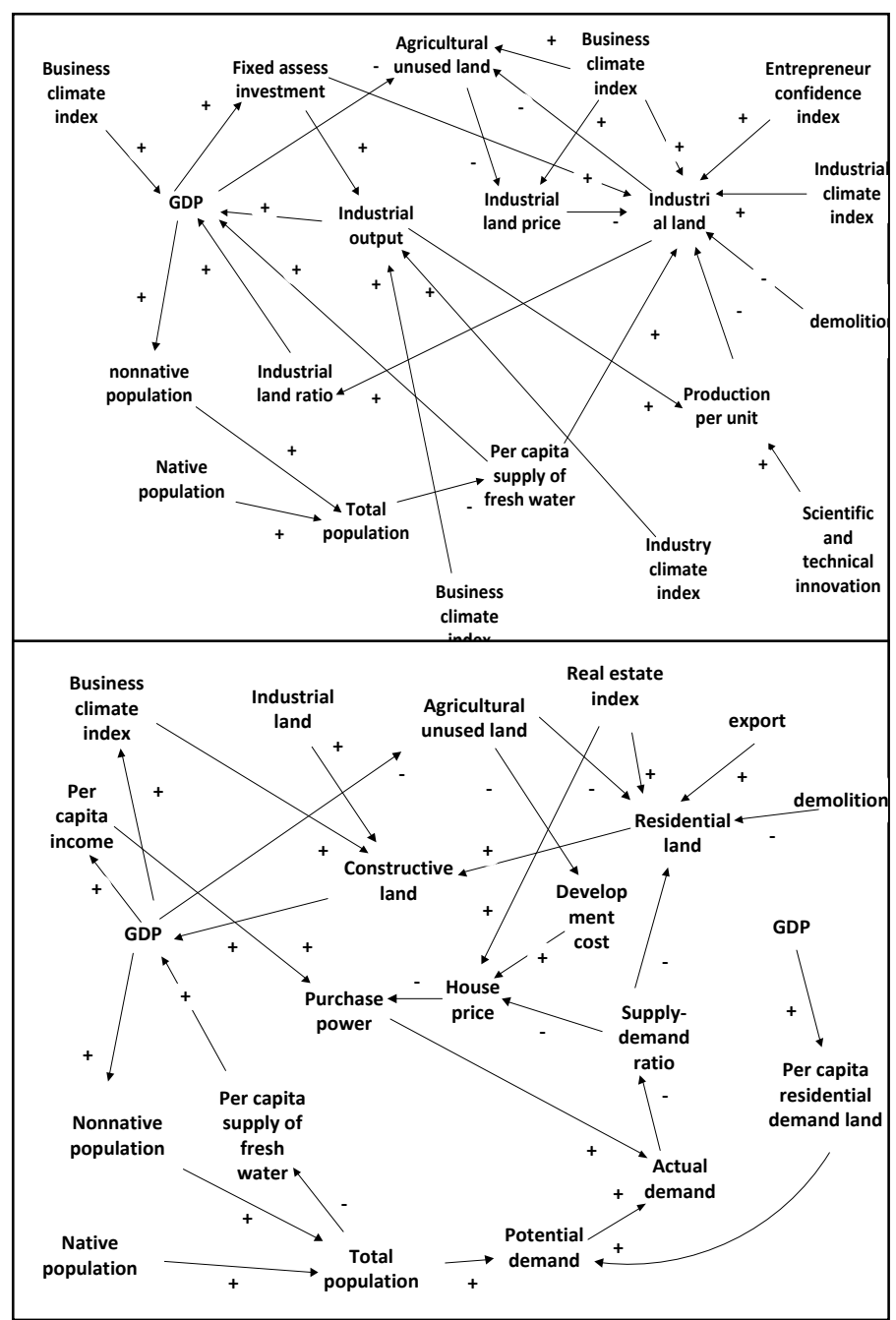

For the traditional CA model is lack of rules for cell evolution, a spatial logistic regression model ${ }^{[11][12]}$ was used to estimate the discrete transitional probabilities of each cell evolving into other land patterns in our improved CA model. By computing the equation of the natural log of the probability of each land use category divided by the probability of the others to find maximize the likelihood, a Bayesian multinomial logistic regression model was applied to estimate the suitability sets of each land cell in order to simulate urban spatial nonlinear urban growth in different scenarios. The equations are showed in the following.

$\sum_{k} \operatorname{Prob}\left(i_{k}\right)=1$

$$
\begin{aligned}
& \operatorname{Prob}\left(i_{1}\right)=\frac{1}{1+\sum_{j=2}^{n} \exp \left(\alpha_{j}+\beta_{j} X_{i}\right)} \\
& \operatorname{Prob}\left(i_{k}\right)=\frac{\exp \left(\alpha_{k}+\beta_{k} X_{i}\right)}{1+\sum_{j=2}^{n} \exp \left(\alpha_{j}+\beta_{j} X_{i}\right)} \quad k=2, \ldots, n
\end{aligned}
$$

$\operatorname{prob}\left(i_{k}\right)$ is the estimated probability of the $\mathrm{i}^{\mathrm{i}^{\text {th }}}$ land cell unit belonged to pattern $\mathrm{k}$. The following variables are constants $\alpha_{j}$, coefficients $\beta_{j}(\mathrm{j}=1,2, \ldots, \mathrm{n})$, and predictors $X_{i}$ for the $\mathrm{n}$ predictor variables $(\mathrm{j}=1,2, \ldots, \mathrm{n})$ of the $\mathrm{i}^{\mathrm{i}^{\text {th }}}$ land cell unit. 


\section{STRUCTURE AND FUNTIONS}

\section{System technology}

Urban land use early system integrated land use scenario models (SD, CA), geographic spatial analysis with RS and GIS technology. The system used historical remote sensing data as an important data source, and GIS technology to build a synthetic platform for management and visualization. And SD model is for macro prediction of land use, CA model for micro. Macro prediction of land use is to make prediction of total areas of each kind of land and Micro is to get land pattern transition results.

The system technology can be depicted simplly as follows. First, use SD model built macro prediction model according to supply-demand relationships and driving factors for calculating total amount of each land. Second, CA model is for micro aspect to get land evolution results in favor of the fitness by logistic model. Then, integrate SD and CA models on GIS platform to share the same interface and exchange correspondent data. The connection between two modules wasdesigned to keep CA evolutions in correspondence with SD predictions. At last, warning indexes were applied into above models to build warning system for mapping warning distribution for land use changes.

\section{System structure}

The urban land use prediction and warning system mainly include four modules: (1) data management and visulizaiton, (2) SD total amount prediciton of earch land, (3) CA land evolution, and (4) spatial warning. (Fig. 2)

- data management and visulizaiton. In this part, we can manage, query and show spatial data, including remote sensing images, land use base maps.

- SD Land total amount prediction. In this module, building, displaying and editing SD flow charts can be realized. It also can modify $\mathrm{SD}$ parameters, $\mathrm{SD}$ calculate and etc.

- CA Land evolution. Two phases are included. First is logistic calculating fitness for CA model using geographic, economic and natural data as independent variables to promote CA accuracy and then is using CA model calculating land evolution. This part can set data for fitness, relative coefficiences and parameters, control layers for CA calculation and analysis CA results. Display static land evolution of each year and make animation display by time.

- $\quad$ Spatial warning. In this part, we calculate warning indexes for each cell and map in district, street and plaque using probability statistics.

\section{Spatial Warning module}

The spatial warning model was designed into three scale of base land: district, street and plaque. Warning indexes were calculated on land expanding pattern, efficiency, ecological influence and capability respectively for each scale. The model was developed in four main procedure: multi-scale warning

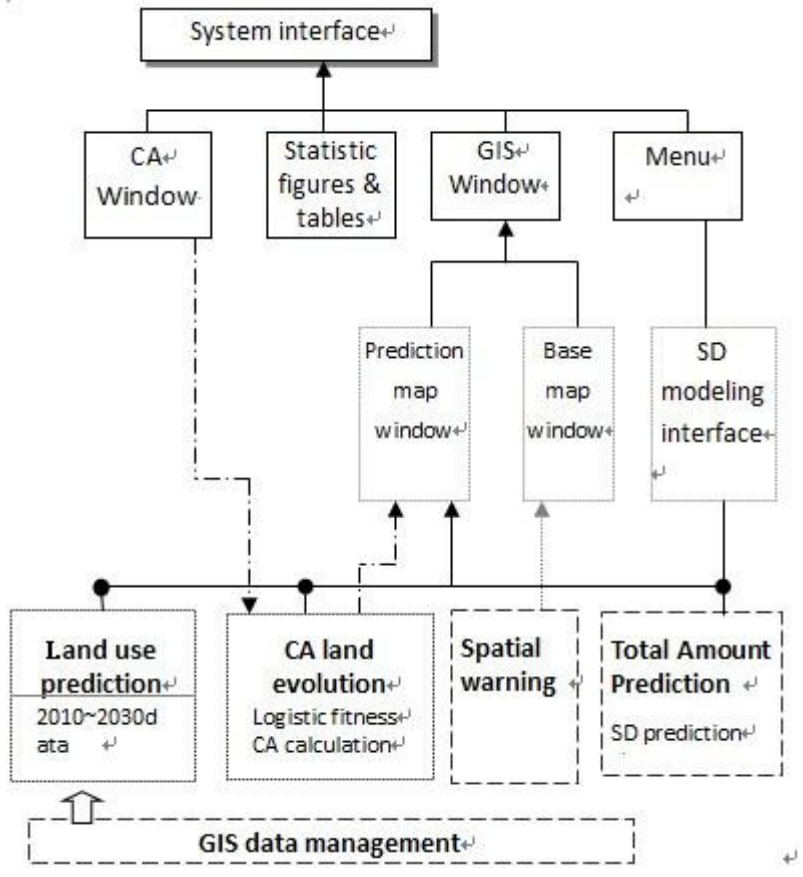

Fig 2. The structure of land urban landuse ealy waning system

indices setting, base land use data management, warning indexes calculation and results display. (Fig. 3)

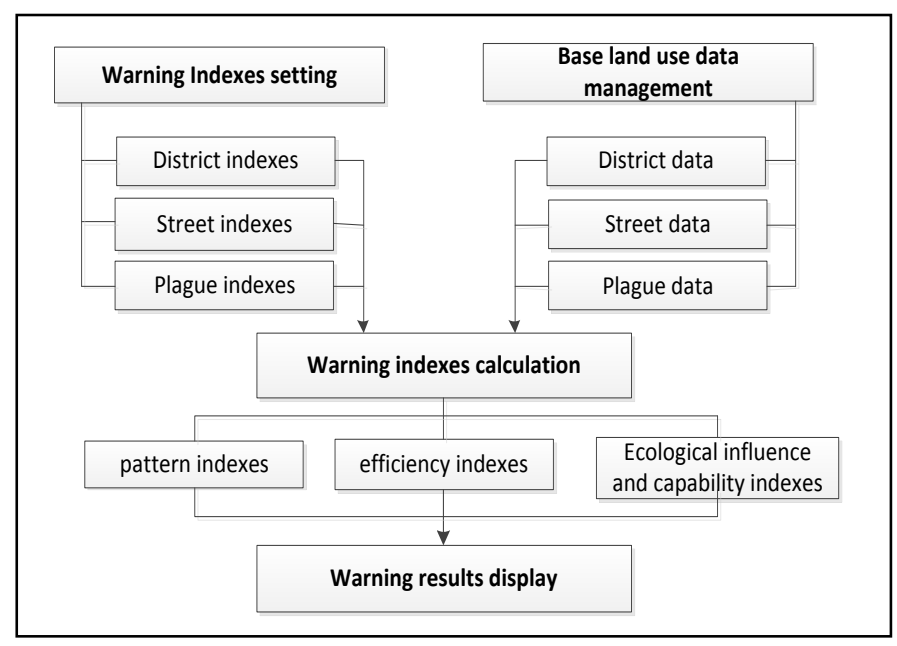

Fig 3. workflow of multi-scale spatial warning model

\section{WARNING RESULT ANALYSIS}

The Urban prediction and warning system was applied in Shenzhen city based on above data from year 2001 and 2008. Shenzhen $\left(113^{\circ} 45^{\prime}-114^{\circ} 28^{\prime}, 22^{\circ} 26^{\prime}-22^{\circ} 52^{\prime}\right)$ is located in the middle south coastal land of Guangdong province in China. Its administrative districts includes Luohu, Futian, Yantian and Nanshan four core districts, Baoan and Longgang two districts outside. Our study area covers the whole Shenzhen city. And we modeled each districts with their own features and simulated one after another.

Figure 4 is the operation window of urban early warning system of Shenzhen. The figure shows each part of the system including SD prediction, data managemant, CA evolution and 
also shows display of evolution results, GIS data and statistic data in figure and results of prediction, fitness calculation and warning in list.

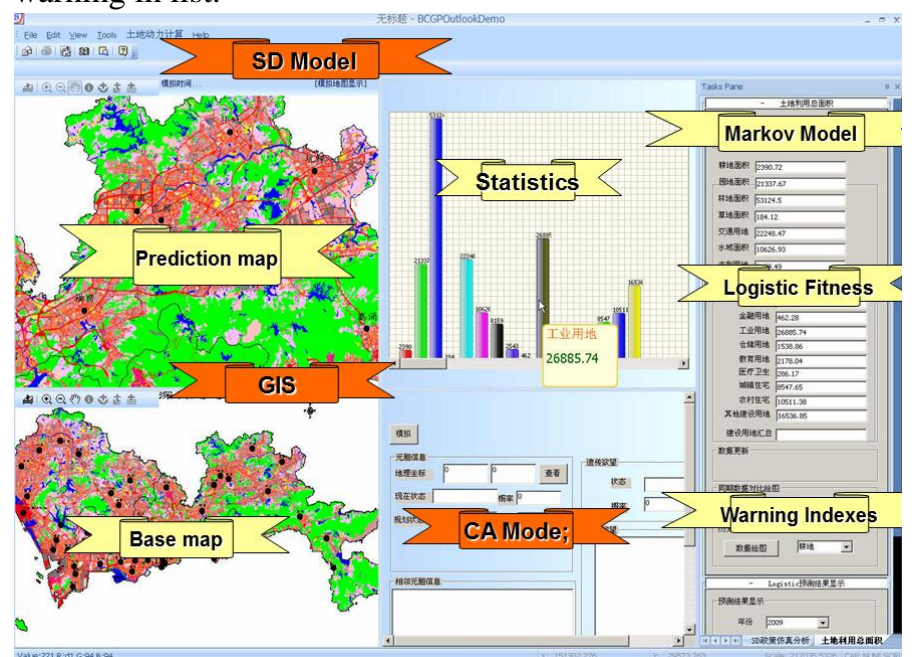

Fig 4. Window of urban early- warning system

At last, prediction results from above ways and surveying data from Shenzhen Real Estate Research Center of industrial and residential land area were applied for assessing precision of proposed model from year 2001 to 2011. Figure 5 illustrates the difference between prediction results and surveying data. The maximum error for industrial land was $6.21 \%$ and occurred in 2009. And the economic depression the maximum error for residential land was $4.77 \%$ in 2011 year.

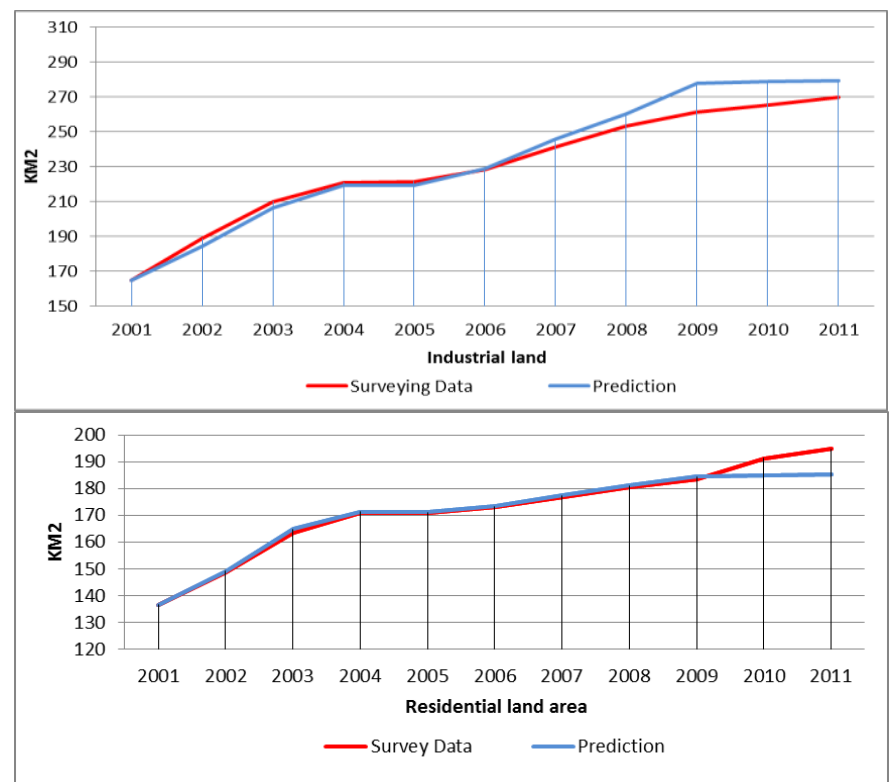

Fig 5. The comparson with predictionand and surveying data for industrial and residential land area

\section{CONCLUSION}

Urban land use prediction and warning can help appropriately sustainable use of land resources. This paper depicts achievement of an urban early-warning system for Shenzhen city according to introducing its structure, function, main models and used data. The results showed that the system had the ability to reflect the complex behavior of land use system, and meet the needs of land use early warning systems and annual planning of land supplies of Shenzhen municipality.

\section{ACKNOWLEDGMENT}

This research was funded by the NSOAS project E03091112-JC01. This support is gratefully acknowledged.

\section{REFERENCES}

[1] J. Wang and J. Li, "Research of early-warning system for landuse[J]," Resource Development and Market, 2006, vol. 22(4), pp.358-360. (In Chinese)

[2] Y. Zhao, Y. Yang, F. Liu and L. Sun, "Establishment of the system of monitoring evaluation and early warning of the land use plan actualization in Beijing[J]," Journal of Arid Land Resources and Environment, 2006, Vol. 20(1), pp.23-26. (In Chinese)

[3] N. Stephenne, E F. Lambin, "Dynamic simulation model for land use changes in Sudano-sahelian countries of Africa[J]," Agric Ecosyst Environ, 2001, vol. 85(1-3), PP.145-162.

[4] P. Verburg, "Land use change modeling at the regional scale the CLUE-S model[J]," Environ Manage, 2003, vol. 30(3), pp.391405.

[5] K. Overmars, G. Koning, A. Veldkamp, "Spatial autocorrelation in multiscale land use models[J]," Ecol Model, 2003, vol. 64(23), pp. 257-270.

[6] Y. Tan, C. Wu, Z. Ye, H. Ding and Y. Mou, "The indicator system and method to assess the sustainability of Urban land use[J]," China Soft Science, 2003, vol.3, pp.139-143. (In Chinese)

[7] Y. Qiao, W. Zhou, Y. Cao, B. Liu and X. Xin, "Study on appraisal indicator system of urban land intensive use[J]," Ecological Economy, 2010, vol.6, pp. (In Chinese)

[8] H. Guo, L. Liu, G. Huang, G. Fuller, R. Zou and Y. Yin, "A system dynamics approach for regional environmental planning and management: A study for the Lake Erhai Basin[J]," Journal of Environmental Management, 2001, vol. 61, pp.93-111.

[9] C. He, N. Okada, Q. Zhang, P. Shi, J. Li, "Modelling dynamic urban expansion[J]," Processes incorporating a potential model with cellular automata. Landscape and Urban Planning, 2008, vol. 86, pp.79-91.

[10] S. Lauf, D. Haase. "Uncovering land-use dynamics driven by human decision-making - A combined model approach using cellular automata and system dynamics[J]," Environmental Modelling \& Software, 2012, vol. 27, pp. 71-82.

[11] P. Luo, X. Cao, Hongga Li and M. Li, "Dynamic simulation of land use change in shenzhen city based on Markov-logistic-CA models", Geoinformatics 2010, pp.1-4. (In Chinese)

[12] H. Li, X. Huang, B. Huang and P. Luo, "Prediction of urban land use evolution using temporal remote sensing data analysis and a spatial logistic model," IGARSS 2010, pp.2751-2753. 